\title{
Pengembangan Skala Keyakinan Irasional dalam Penulisan Skripsi
}

\author{
Diniy Hidayatur Rahman* \\ Jurusan Bimbingan dan Konseling, Fakultas Ilmu Pendidikan, Universitas Negeri Malang, \\ Jl. Semarang No. 5, Malang, Jawa Timur, Indonesia 65145 \\ *Penulis koresponden, e-mail: diniy.hidayatur.fip@um.ac.id
}

Artikel diterima: 24 Februari 2019; direvisi: 25 Maret 2019; disetujui: 30 Maret 2019

\begin{abstract}
Previous studies have shown that irrational beliefs contribute significantly to the procrastination, including the thesis-writing procrastination. Unfortunately, there are no scales that specifically can measure the beliefs in the thesis writing context. Therefore, this study aimed to develop and validate a scale called the Skala Keyakinan Irasional dalam Penyusunan Skripsi (SKI-S). The scale was developed based on irrational belief construct proposed by Albert Ellis in the context of thesis writing. To achieve the aim, the study applied a research and development design involving four steps: (1) defining the construct; (2) developing the measurement model; (3) carrying out confirmatory factor analysis; and (4) checking the validity of the measurement model. 200 undergraduate students taking their 9 th to 14 th semester were involved in the study. 86 items were successfully validated which were classified into demandingness subscale (16 items); catastrophizing subscale (20 items); self-depreciation subscale (17 items); and low frustration tolerance subscales (20 items).
\end{abstract}

Keywords: irrational beliefs; scale; thesis writing

\begin{abstract}
Abstrak: Beberapa hasil penelitian membuktikan bahwa keyakinan irasional berkontribusi pada terjadinya prokrastinasi, termasuk prokrastinasi dalam penulisan skripsi. Sampai saat ini belum dijumpai alat ukur yang secara khusus mengukur keyakinan irasional dalam konteks dimaksud. Penelitian ini bertujuan untuk mengembangkan sebuah alat ukur yang diberi nama Skala Keyakinan Irasional dalam Penyusunan Skripsi (SKI-S). Skala ini dikembangkan berdasarkan konstruk keyakinan irasional yang dikemukakan oleh Albert Ellis dengan menambahkan konteks penulisan skripsi ke dalam butir-butir skala. Untuk mencapai tujuan yang telah disebutkan, penelitian ini menggunakan desain penelitian pengembangan dengan langkah-langkah: (1) mendefinisikan konstruk; (2) mengembangkan model pengukuran; (3) melakukan analisis faktor konfirmatori; dan (4) mengecek validitas model pengukuran. Subjek yang terlibat dalam pengembangan ini adalah 200 mahasiswa yang terlambat lulus (sedang menempuh semester sembilan hingga 14). Hasil menunjukkan 86 butir SKI-S valid dan reliabel, sedangkan 178 butir lainnya tidak memenuhi syarat. Secara rinci, 86 butir tersebut terdiri dari: 16 butir subskala demandingness; 20 butir subskala catastrophizing; 17 butir subskala self-depreciation; dan 20 butir subskala low frustration tolerance.
\end{abstract}

Kata kunci: keyakinan irasional; skala; skripsi

\section{PENDAHULUAN}

Keyakinan irasional merupakan salah satu variabel yang memiliki pengaruh besar pada perilaku prokrastinasi dalam penulisan skripsi (Dryden, 2012). Sebuah penelitian menunjukkan bahwa discomfort intolerance belief yang merupakan salah satu bentuk keyakinan irasional berkorelasi positif dengan prokrastinasi (Harrington, 2005). Temuan tersebut didukung pula oleh penelitian lain yang menunjukkan bahwa keyakinan irasional memiliki pengaruh signifikan dan langsung pada prokrastinasi (Balkis dkk., 2013). Penelitian lain juga menunjukkan bahwa ada hubungan antara keyakinan irasional dan prokrastinasi (Ozer dkk., 2013). Dalam penelitian dengan desain eksperimen tersebut, intervensi

Cara mengutip: Rahman, D. H. (2019). Pengembangan Skala Keyakinan Irasional dalam Penulisan Skripsi. Jurnal Kajian Bimbingan dan Konseling, 4(1), 1-12. https://doi.org/10.17977/um001v4i12019p001 
yang dilakukan untuk mengeliminasi keyakinan-keyakinan irasional terbukti efektif untuk menurunkan prokrastinasi akademik para subjek. Hal ini berarti bahwa jika keyakinan irasional terkait prokrastinasi menurun, prokrastinasi akademik juga akan menurun, demikian pula sebaliknya.

Hasil-hasil penelitian seperti telah disebutkan, berimplikasi pada perlunya perhatian khusus pada variabel keyakinan irasional dalam upaya intervensi dan pencegahan terhadap perilaku prokrastinasi dalam penulisan skripsi. Dengan memiliki data tentang jenis irasionalitas yang berkontribusi pada prokrastinasi dalam penulisan skripsi, konselor sekolah dapat melakukan identifikasi awal serta menyiapkan intervensi spesifik tertentu terhadap irasionalitas dimaksud. Sayangnya, sampai saat ini masih belum ditemukan instrumen yang secara spesifik dapat mengukur keyakinan irasional dalam konteks penulisan skripsi. Instrumen-instrumen yang ada sementara ini hanya dapat mengukur keyakinan irasional dalam konteks umum sehingga penggunaannya untuk konteks penulisan skripsi belum betulbetul tepat sasaran. Beberapa instrumen dimaksud antara lain adalah: (1) BS (The Belief Scale) (Malouff \& Schutte, 1986); (2) ABS-II (Attitudes and Beliefs Scale II) (DiGiuseppe dkk., 2018) yang merupakan hasil revisi dari $A B S$-I yang disusun oleh Burgess, (1986). Karena jumlah butir $A B S$-II yang terlampau banyak, Hyland dkk., (2014) mengembangkan versi ringkasnya; dan (3) RAIBS (Rational and Irrational Beliefs Scale) (Mogoase dkk., 2013). Tiga instrumen tersebut merupakan alat ukur keyakinan irasional yang banyak dimanfaatkan dalam berbagai penelitian dan konseling/psikoterapi, serta telah memiliki kelayakan psikometris yang memadai.

Sebuah review telah dilakukan terhadap beberapa alat ukur keyakinan irasional dan menghasilkan beberapa rekomendasi untuk pengembangan alat ukur dimaksud (Terjesen dkk., 2009). Di antara rekomendasi tersebut adalah: (1) instrumen hendaknya hanya mengukur keyakinan semata, tanpa bercampur dengan konsekuensi emotif atau behavioral; (2) instrumen hendaknya mengukur keyakinan rasional dan irasional secara terpisah karena keduanya bukan konstruk yang bipolar; (3) instrumen hendaknya mengukur dimensi dan konteks keyakinan irasional; dan (4) dalam proses pengembangannya, instrumen hendaknya menggunakan sampel yang bermacam-macam.

Berdasarkan rekomendasi pertama, dapat diketahui bahwa alat ukur keyakinan irasional yang baik adalah instrumen yang hanya mengukur aspek kognitif dari keyakinan irasional tanpa mencampurkannya dengan aspek afektif maupun perilaku. Hal ini sesuai dengan pernyataan Ellis dkk., (2010) bahwa keyakinan irasional adalah pikiran-pikiran evaluatif yang ditujukan pada diri sendiri; orang lain; dan atau lingkungan; yang bersifat ekstrim; kaku; dan absolutistik; serta tidak logis; tidak berdasar pada realitas; dan menghalangi individu untuk mencapai tujuan-tujuannya. Terdapat empat klasifikasi keyakinan irasional yang seluruhnya merupakan aspek kognitif, yaitu: demandingness; catastrophizing; selfdepreciation; dan low frustration tolerance (Ellis dkk., 2010). Dengan demikian, memasukkan unsur afektif dan perilaku sebagai bagian dari alat ukur keyakinan irasional bertentangan dengan konstruk keyakinan irasional itu sendiri.

Berdasarkan rekomendasi kedua, butir-butir alat ukur keyakinan irasional harus merupakan butirbutir yang mengukur keyakinan irasional dan bukan keyakinan rasional. Hal ini karena keyakinan irasional bukan sekedar kebalikan dari keyakinan rasional, namun keduanya merupakan konstruk yang berbeda. Karenanya, butir-butir keyakinan irasional harus dikembangkan dari konstruk keyakinan irasional, sedangkan butir-butir keyakinan rasional harus dikembangkan dari konstruk keyakinan rasional. Terdapat empat klasifikasi keyakinan irasional yang seluruhnya merupakan aspek kognitif, yaitu: demandingness; catastrophizing; self-depreciation; dan low frustration tolerance (Ellis dkk., 2010). Demandingness adalah tuntutan individu yang bersifat kaku dan absolut agar sesuatu terjadi atau tidak terjadi. Alternatif rasional dari demandingness adalah preference, di mana individu menginginkan agar sesuatu terjadi atau tidak terjadi tanpa tuntutan yang kaku dan absolut. Catastrophizing adalah penilaian hiperbolis individu bahwa keburukan sesuatu lebih dari 100\%. Alternatif rasional dari catastrophizing adalah anti-catastrophizing, dimana individu menilai sebuah keburukan secara normal sesuai dengan fakta yang terjadi dan tidak terkungkung olehnya. Self-depreciation didefinisikan sebagai penilaian negatif individu terhadap dirinya sendiri saat tuntutan-tuntutannya terhadap dirinya sendiri; orang lain; dan atau lingkungan tidak terpenuhi. Alternatif rasional dari self-depreciation adalah unconditional selfacceptance, dimana individu menerima dirinya secara positif tanpa menghiraukan kondisi apapun. Low frustration tolerance didefinisikan sebagai tuntutan-tuntutan individu terhadap dirinya sendiri, orang lain, atau lingkungan agar ia tidak mengalami kondisi yang tidak nyaman. Alternatif rasional dari low 
frustration tolerance adalah high frustration tolerance, di mana individu sanggup bertahan dan bersedia menerima tekanan untuk mendapatkan kepuasan jangka panjang (Dryden \& Neenan, 2004; Rahman, 2016; Szentagotai \& Jones, 2010).

Merujuk pada rekomendasi ketiga, dapat dimaknai bahwa instrumen keyakinan irasional harus mengukur konteks yang spesifik. Dalam hal ini, keyakinan irasional dalam penulisan skripsi harus diukur dengan alat ukur keyakinan irasional yang berisi butir-butir yang terkait dengan konteks penulisan skripsi. Penggunaan instrumen keyakinan irasional umum untuk mengukur keyakinan irasional dalam penulisan skripsi akan menjadi kurang tepat. Adapun pada rekomendasi keempat, dapat diketahui bahwa sampel yang digunakan untuk proses validasi instrumen harus merupakan sampel yang representatif dan beragam. Penggunaan sampel yang kecil dan homogen akan membuat instrumen tidak dapat digunakan secara luas.

Berdasarkan latar belakang dan kajian-kajian penelitian terdahulu, penelitian ini bertujuan untuk mengembangkan skala keyakinan irasional dalam konteks penulisan skripsi. Secara umum, skala tersebut akan memiliki spesifikasi sebagai skala yang: (1) hanya mengukur aspek kognitif dari keyakinan irasional; (2) mengukur konstruk keyakinan irasional semata (tanpa keyakinan rasional) yang dikembangkan dari konstruk demandingness; catastrophizing; self-depreciation; dan low frustration tolerance; dan (3) menggunakan konteks penulisan skripsi sebagai konten dari keyakinan irasional.

\section{METODE}

\section{Rancangan Penelitian}

Penelitian ini menggunakan rancangan penelitian pengembangan, dimana akan dihasilkan sebuah alat ukur yang disebut SKI-S. Untuk mengembangkan instrumen dimaksud, penelitian ini mengikuti langkah-langkah Hair dkk., (2006) yaitu: (1) mendefinisikan konstruk yang mendasari alat ukur; (2) mengembangkan model pengukuran konstruk; (3) melakukan analisis faktor konfirmatori untuk menguji secara empirik apakah konstruk yang dikembangkan confirm atau tidak confirm terhadap teori; dan (4) mengevaluasi validitas model pengukuran yang disusun pada langkah 2 dan 3 . Hasil langkah ini berupa revisi butir dan indikator yang telah dikembangkan pada langkah 1.

\section{Subjek Penelitian}

Subjek penelitian ini adalah 200 mahasiswa Universitas Negeri Malang (UM) yang terlambat menyelesaikan skripsi. Jumlah tersebut diperoleh dengan teknik multistage cluster sampling. Pada tahap awal, peneliti mengidentifikasi jumlah mahasiswa yang terlambat menyelesaikan skripsi (sedang menempuh semester sepuluh ke atas dan memprogram matakuliah penulisan skripsi pada semester genap tahun 2018) pada delapan fakultas di UM: Fakultas Ilmu Pendidikan (FIP); Fakultas Sastra (FS); Fakultas Matematika dan Ilmu Pengetahuan Alam (FMIPA); Fakultas Ekonomi (FE); Fakultas Teknik (FT); Fakultas Ilmu Keolahragaan (FIK); Fakultas Ilmu Sosial (FIS); dan Fakultas Pendidikan Psikologi (FPPsi). Rincian populasi secara lengkap ditampilkan pada tabel 1.

Tabel 1. Rincian Populasi Penelitian

\begin{tabular}{lcccc}
\hline Fakultas & Angkatan 2011 & Angkatan 2012 & Angkatan 2013 & $\sum$ \\
\hline FIP & 82 & 71 & 150 & 303 \\
FS & 146 & 220 & 368 & 734 \\
FMIPA & 25 & 83 & 151 & 259 \\
FE & 80 & 195 & 301 & 576 \\
FT & 139 & 315 & 441 & 895 \\
FIK & 53 & 99 & 255 & 407 \\
FIS & 70 & 140 & 238 & 448 \\
FPPsi & 19 & 20 & 88 & 127 \\
$\sum$ & 614 & 1143 & 1992 & 3749 \\
\hline
\end{tabular}


Selanjutnya, berdasarkan pengelompokan mahasiswa menurut fakultas, dipilih $25 \%$ program studi dari setiap fakultas secara acak. Berdasarkan proses ini, diperoleh 17 sampel program studi dengan rincian sebagai berikut: (1) dua program studi dari FIP; (2) tiga program studi dari FS; (3) tiga program studi dari FMIPA; (4) dua program studi dari FE; (5) tiga program studi dari FT; (6) satu program studi dari FIK; (7) dua program studi dari FIS; dan (8) satu program studi dari FPPsi. Terakhir, peneliti mengidentifikasi jumlah mahasiswa yang terlambat menyelesaikan skripsi pada masing-masing program studi yang terpilih sebagai sampel. Dari jumlah mahasiswa tersebut, ditentukan sampel secara acak sebesar 200 mahasiswa. Secara lengkap, jumlah subjek dari setiap program studi sampel ditampilkan dalam tabel 2.

\section{Prosedur Pengumpulan Data}

Data penelitian didapatkan dengan prosedur: (1) memperoleh data jumlah mahasiswa yang terlambat lulus di Pusat Teknologi Informasi dan Komunikasi UM; (2) memilih subjek dengan teknik multistage cluster sampling; (3) menghubungi subjek terpilih melalui nomor telepon dan/atau email; dan (4) meminta kesediaan para subjek untuk mengisi instrumen SKI-S uji coba secara online atau offline. Jika seorang subjek tidak bersedia berpartisipasi, maka dipilih subjek lain secara acak dari program studi yang sama.

\section{Analisis Data}

Validitas konstruk instrumen dianalisis dengan menggunakan analisis faktor eksploratori. Analisis faktor eksploratori dilakukan dengan menggunakan SPSS 20. Analisis ini dimulai dengan melihat nilai Kaiser-Meyer-Olkin (KMO)-Measure Sampling Adequacy (MSA) untuk menilai kelayakan seluruh butir. Jika nilai $K M O-M S A \geq 0,5$ dengan $\mathrm{p} \leq 0,05$, maka analisis dapat dilanjutkan. Di samping itu, jika nilai $M S A$ setiap butir $\geq 0,5$, maka butir tersebut layak untuk dianalisis. Sebaliknya, jika nilai $M S A<0,5$, maka butir tersebut harus digugurkan. Langkah berikutnya adalah ekstraksi butir yang layak dengan metode varimax. Butir-butir yang memiliki loading $\geq 0,5$ terhadap indikator pada satu dimensi yang dikembangkan akan ditetapkan sebagai butir yang layak. Namun demikian, butir tersebut akan dianggap tidak memenuhi asumsi teoretik jika terekstrak ke suatu indikator yang tidak tepat. Dengan demikian,

Tabel 2. Jumlah Sampel Berdasarkan Fakultas dan Program Studi

\begin{tabular}{lcc}
\hline Fakultas & Jurusan/Program Studi & Jumlah Sampel \\
\hline FIP & FIP 1 & 18 \\
& FIP 2 & 8 \\
FS & FS 1 & 9 \\
& FS 2 & 11 \\
FMIPA & FS 3 & 6 \\
& FMIPA 1 & 10 \\
& FMIPA 1 & 11 \\
FE & FMIPA 1 & 5 \\
& FE 1 & 6 \\
FT & FE 2 & 20 \\
& FT 1 & 11 \\
& FT 2 & 10 \\
FIK & FT 3 & 5 \\
FIS & FIK 1 & 26 \\
& FIS 1 & 13 \\
FPPsi & FIS 2 & 13 \\
& FPPsi 1 & 18 \\
\hline
\end{tabular}


butir tersebut harus dibuang meskipun secara statistik memiliki loading $\geq 0,5$. Selanjutnya, indikatorindikator yang memiliki loading $\geq 0,5$ terhadap suatu konstruk yang dikembangkan akan ditetapkan sebagai indikator yang layak.

Butir-butir dan indikator-indikator yang valid berdasarkan analisis faktor eksploratori tersebut kemudian diuji reliabilitasnya dengan teknik Alpha Cronbach. Kriteria koefisien Alpha Cronbach yang digunakan dalam hal ini adalah $>0,7$. Analisis Alpha Cronbach dilakukan dengan menggunakan SPSS 20.

Pengujian selanjutnya dilakukan dengan analisis faktor konfirmatori yang menggunakan teknik second order (Hair dkk., 2006). Analisis ini digunakan untuk menguji unidimensionalitas SKI-S. Unidimensionalitas dalam hal ini ditentukan oleh nilai Root Mean Square Error of Approximation $(R M S E A) \geq 0,08$ (Hair dkk., 2006). Validitas butir terhadap indikator dan indikator terhadap konstruk ditentukan oleh nilai lambda $\geq 0,4$ (Ferdinand, 2002; Hair dkk., 2006). Analisis faktor konfirmatori ini dilakukan dengan menggunakan Lisrel 8.80 versi student.

\section{HASIL}

\section{Blueprint Awal SKI-S}

Berdasarkan kajian terhadap konstruk keyakinan irasional yang dikemukakan oleh Ellis dkk., (2010) dan hasil studi pendahuluan tentang konteks penulisan skripsi, peneliti mengkonstruksi 264 butir pernyataan yang diekstraksi dari empat subvariabel dan 24 indikator. Deskripsi subvariabel, jumlah indikator; jumlah butir; dan contoh butir tersebut diilustrasikan dalam tabel 3. Pada setiap butir, dikembangkan empat pilihan jawaban Skala Likert mulai dari tidak sesuai hingga sangat sesuai.

\section{SKI-S Pasca Uji Ahli}

Setelah dilakukan pengujian pada lima ahli, tersisa 180 butir valid dari total 264 butir. Adapun 84 butir lainnya dieliminasi karena dinilai para ahli tidak valid atau tumpang tindih dengan butir lainnya. Secara detail, deskripsi blueprint SKI-S pasca uji ahli disajikan dalam tabel 4. Dari tabel 4, diketahui bahwa masing-masing indikator memiliki jumlah butir gugur yang sama. Hal ini terjadi karena masingmasing subvariabel memiliki indikator yang mirip sehingga pengguguran sebuah butir di salah satu indikator berimplikasi pada pengguguran butir sejenis di subvariabel lainnya.

\section{SKI-S Pasca Analisis Faktor dan Alpha Chronbach}

\section{Subskala Demandingness}

Validitas dan reliabilitas 45 butir subvariabel demandingness diuji secara statistik dengan menggunakan analisis faktor eksploratori; Alpha Chronbach; dan analisis faktor konfirmatori. Hasil pengujian dengan analisis faktor eksploratori, diketahui enam belas butir yang memiliki loading factor $\geq 0,5$ dan 29 butir memiliki loading factor $<0,5$. Dengan demikian, hanya tersisa enam belas butir subvariabel demandingness yang valid. Enam belas butir tersebut juga mengelompok dalam tiga indikator. Butir $8 ; 9 ; 11 ; 12 ; 13$; dan 16 mengelompok dalam indikator tuntutan kaku terkait penulisan bagian-bagian skripsi, butir 31; 33; 34; 35; dan 36 mengelompok dalam indikator tuntutan kaku terkait kegiatan konsultasi pada dosen pembimbing, dan butir 37; 39; 42; 43; dan 45 mengelompok dalam indikator tuntutan kaku dalam merevisi tulisan sebelumnya. 16 butir tersebut kemudian diuji reliabilitasnya dengan Alpha Chronbach. Hasil pengujian menunjukkan bahwa 16 butir tersebut reliabel karena memiliki koefisien Alpha Chronbach > 0,7. Hasil-hasil pengujian tersebut dirangkum dalam tabel 5.

16 butir tersebut kemudian diuji kembali dengan analisis faktor konfirmatori untuk mengetahui unidimensionalitas model pengukuran dan validitas setiap butir. Berdasarkan hasil pengujian ini, diketahui bahwa $R M S E A=0,046$ yang berarti baik, serta Chi-Square $=173,18$ dengan probabilitas sebesar 0,07623 yang berarti model pengukuran yang dikembangkan telah memperoleh dukungan empiris yang memadai. Demikian pula, lambda seluruh butir ke indikator dan indikator ke subvariabel demandingness $>0,4$ yang berarti bahwa butir-butir dan indikator-indikator tersebut valid. 
Tabel 3. Blueprint Awal SKI-S

\begin{tabular}{|c|c|c|c|c|}
\hline Variabel & Subvariabel & & Indikator & $\begin{array}{l}\text { Jumlah } \\
\text { butir }\end{array}$ \\
\hline \multirow{24}{*}{$\begin{array}{l}\text { Keyakinan irasional } \\
\text { dalam penyusunan } \\
\text { skripsi }\end{array}$} & \multirow{6}{*}{$\begin{array}{l}\text { Tuntutan absolut } \\
\text { (demandingness) } \\
\text { dalam penyusunan } \\
\text { skripsi }\end{array}$} & 1. & Tuntutan absolut terkait penggunaan bahan pustaka & 11 \\
\hline & & & Tuntutan absolut terkait penulisan bagian skripsi & 15 \\
\hline & & & $\begin{array}{l}\text { Tuntutan absolut terkait kegiatan penelitian } \\
\text { lapangan }\end{array}$ & 10 \\
\hline & & & $\begin{array}{l}\text { Tuntutan absolut terkait kegiatan diskusi dengan } \\
\text { orang ketiga }\end{array}$ & 6 \\
\hline & & & $\begin{array}{l}\text { Tuntutan absolut terkait konsultasi dengan } \\
\text { pembimbing }\end{array}$ & 12 \\
\hline & & & $\begin{array}{l}\text { Tuntutan absolut terkait merevisi tulisan } \\
\text { sebelumnya }\end{array}$ & 12 \\
\hline & \multirow{6}{*}{$\begin{array}{l}\text { Pemalapetakaan } \\
\text { (catastrophizing) } \\
\text { dalam penyusunan } \\
\text { skripsi }\end{array}$} & & Pemalapetakaan terkait penggunaan bahan pustaka & 11 \\
\hline & & & Pemalapetakaan terkait penulisan bagian skripsi & 15 \\
\hline & & & $\begin{array}{l}\text { Pemalapetakaan terkait kegiatan penelitian } \\
\text { lapangan }\end{array}$ & 10 \\
\hline & & & $\begin{array}{l}\text { Pemalapetakaan terkait kegiatan diskusi dengan } \\
\text { orang ketiga }\end{array}$ & 6 \\
\hline & & & $\begin{array}{l}\text { Pemalapetakaan terkait konsultasi dengan } \\
\text { pembimbing }\end{array}$ & 12 \\
\hline & & & $\begin{array}{l}\text { Pemalapetakaan terkait merevisi tulisan } \\
\text { sebelumnya }\end{array}$ & 12 \\
\hline & \multirow{6}{*}{$\begin{array}{l}\text { Perendahan diri } \\
\text { (self-depreciation) } \\
\text { dalam penyusunan } \\
\text { skripsi }\end{array}$} & & Perendahan diri terkait penggunaan bahan pustaka & 11 \\
\hline & & & Perendahan diri terkait penulisan bagian skripsi & 15 \\
\hline & & & Perendahan diri terkait kegiatan penelitian lapangan & 10 \\
\hline & & & $\begin{array}{l}\text { Perendahan diri terkait kegiatan diskusi dengan } \\
\text { orang ketiga }\end{array}$ & 6 \\
\hline & & & $\begin{array}{l}\text { Perendahan diri terkait konsultasi dengan } \\
\text { pembimbing }\end{array}$ & 12 \\
\hline & & & Perendahan diri terkait merevisi tulisan sebelumnya & 12 \\
\hline & \multirow{6}{*}{$\begin{array}{l}\text { Toleransi rendah } \\
\text { pada frustrasi } \\
\text { (low frustration } \\
\text { tolerance) dalam } \\
\text { penyusunan } \\
\text { skripsi }\end{array}$} & & $\begin{array}{l}\text { Toleransi rendah terhadap frustrasi terkait } \\
\text { penggunaan bahan pustaka }\end{array}$ & 11 \\
\hline & & 2. & $\begin{array}{l}\text { Toleransi rendah terhadap frustrasi dalam penulisan } \\
\text { bagian skripsi }\end{array}$ & 15 \\
\hline & & & $\begin{array}{l}\text { Toleransi rendah terhadap frustrasi dalam kegiatan } \\
\text { penelitian lapangan }\end{array}$ & 10 \\
\hline & & & $\begin{array}{l}\text { Toleransi rendah terhadap frustrasi dalam kegiatan } \\
\text { diskusi dengan orang ketiga }\end{array}$ & 6 \\
\hline & & & $\begin{array}{l}\text { Toleransi rendah terhadap frustrasi dalam } \\
\text { konsultasi dengan pembimbing }\end{array}$ & 12 \\
\hline & & & $\begin{array}{l}\text { Toleransi rendah terhadap frustrasi dalam merevisi } \\
\text { tulisan sebelumnya }\end{array}$ & 12 \\
\hline \multicolumn{2}{|c|}{ Jumlah } & 24 & & 264 \\
\hline
\end{tabular}

\section{Subskala Catastrophizing}

Empat puluh lima butir subvariabel catastrophizing diuji secara statistik menggunakan analisis faktor eksploratori; Alpha Chronbach; dan analisis faktor konfirmatori. Hasil pengujian dengan analisis faktor eksploratori, menunjukkan 20 butir memiliki loading factor $\geq 0,5$ dan 25 butir memiliki loading factor $<0,5$. Dengan demikian, hanya tersisa 20 butir subvariabel catastrophizing yang valid. 20 butir tersebut juga mengelompok dalam empat indikator. Butir 1; 3 dan 6 mengelompok dalam indikator pemalapetakaan dalam penggunaan bahan pustaka, butir $8 ; 10 ; 11 ; 13 ; 14 ; 15 ; 16$ dan 18 mengelompok dalam indikator pemalapetakaan dalam penulisan bagian-bagian skripsi, butir $30 ; 31$; 35 dan 36 mengelompok dalam indikator pemalapetakaan dalam kegiatan konsultasi pada dosen 
Tabel 4. Blueprint SKI-S Pasca Uji Ahli

\begin{tabular}{|c|c|c|c|c|c|}
\hline Variabel & Subvariabel & $\begin{array}{l}\text { Jumlah } \\
\text { Indikator }\end{array}$ & $\begin{array}{l}\text { Jumlah } \\
\text { Butir } \\
\text { Gugur }\end{array}$ & $\begin{array}{l}\text { Sisa } \\
\text { Butir } \\
\text { Valid }\end{array}$ & Nomor Butir \\
\hline \multirow{4}{*}{$\begin{array}{l}\text { Keyakinan } \\
\text { irasional } \\
\text { dalam } \\
\text { penyusunan } \\
\text { skripsi }\end{array}$} & $\begin{array}{l}\text { Tuntutan absolut (demandingness) } \\
\text { dalam penyusunan skripsi }\end{array}$ & 6 & 21 & 45 & $\begin{array}{l}\text { Subskala } \\
\text { demandingness } 1-45\end{array}$ \\
\hline & $\begin{array}{l}\text { Pemalapetakaan (catastrophizing) } \\
\text { dalam penyusunan skripsi }\end{array}$ & 6 & 21 & 45 & $\begin{array}{l}\text { Subskala } \\
\text { catastrophizing } 1-45\end{array}$ \\
\hline & $\begin{array}{l}\text { Perendahan diri (self-depreciation) } \\
\text { dalam penyusunan skripsi }\end{array}$ & 6 & 21 & 45 & $\begin{array}{l}\text { Subskala self- } \\
\text { depreciation } 1-45\end{array}$ \\
\hline & $\begin{array}{l}\text { Toleransi rendah pada frustrasi } \\
\text { (low frustration tolerance) dalam } \\
\text { penyusunan skripsi }\end{array}$ & 6 & 21 & 45 & $\begin{array}{l}\text { Subskala low frustration } \\
\text { tolerance } 1-45\end{array}$ \\
\hline
\end{tabular}

Tabel 5. Kisi-kisi Subskala Demandingness Pasca Analisis Faktor Eksploratori dan Alpha Cronbach

\begin{tabular}{llccc}
\hline \multicolumn{1}{c}{ Subvariabel } & \multicolumn{1}{c}{ Indikator Valid } & $\begin{array}{c}\text { No. Butir } \\
\text { Valid }\end{array}$ & $\begin{array}{c}\text { Loading } \\
\text { Factor }\end{array}$ & Alpha Cronbach \\
\hline Tuntutan absolut & Tuntutan absolut dalam penulisan & 8 & 0,809 \\
(demandingness) & bagian-bagian skripsi & 9 & 0,751 \\
dalam penyusunan & (loading factor: 0,682) & 11 & 0,741 \\
& & 12 & 0,882 \\
& & 13 & 0,781 \\
& Tuntutan absolut dalam & 16 & 0,652 \\
& kegiatan konsultasi pada dosen & 31 & 0,693 \\
& pembimbing & 33 & 0,644 \\
& (loading factor: 0,867) & 34 & 0,792 \\
& & 35 & 0,916 \\
& & 36 & 0,741 \\
& & 37 & 0,780 \\
& Tuntutan absolut dalam merevisi & 39 & 0,592 \\
& tulisan sebelumnya & & 0,785 \\
& (loading factor: 0,765) & 42 & 0,824 \\
& & 43 & 0,813 \\
\hline
\end{tabular}

pembimbing, sedangkan butir 41; 42; 43; 44 dan 45 mengelompok dalam indikator pemalapetakaan dalam kegiatan merevisi tulisan sebelumnya. Dua puluh butir tersebut kemudian diuji reliabilitasnya dengan Alpha Chronbach. Hasil pengujian menunjukkan bahwa dua puluh butir tersebut reliabel karena memiliki koefisien Alpha Cronbach > 0,7. Hasil-hasil pengujian tersebut dirangkum dalam tabel 6 . Dua puluh butir tersebut kemudian diuji kembali dengan analisis faktor konfirmatori untuk mengetahui unidimensionalitas model pengukuran dan validitas setiap butir. Berdasarkan hasil pengujian ini, diketahui bahwa $R M S E A=0,054$ yang berarti baik, serta nilai Chi-Square $=188,22$ dengan probabilitas sebesar 0,07631 yang berarti model pengukuran yang dikembangkan telah memperoleh dukungan empiris yang memadai. Demikian pula, lambda seluruh butir ke indikator dan indikator ke subvariabel catastrophizing $>0,4$ yang berarti bahwa butir-butir dan indikator-indikator tersebut valid.

\section{Subskala Self-Depreciation}

Empat puluh lima butir subvariabel self-depreciation pasca uji ahli, diuji secara statistik dengan menggunakan analisis faktor eksploratori, Alpha Chronbach, dan analisis faktor konfirmatori. Berdasarkan hasil pengujian dengan analisis faktor eksploratori, diperoleh tujuh belas butir yang memiliki loading factor $\geq 0,5$ dan 28 butir yang memiliki loading factor $<0,5$. Dengan demikian, hanya tersisa tujuh belas butir subvariabel self-depreciation yang valid. tujuh belas butir tersebut juga mengelompok dalam 
$\boldsymbol{8} \mid$ Jurnal Kajian Bimbingan dan Konseling, 4(1), 2019, 1-12

Tabel 6. Kisi-kisi Subskala Catastrophizing Pasca Analisis Faktor Eksploratori dan Alpha Cronbach

\begin{tabular}{|c|c|c|c|c|}
\hline Subvariabel & Indikator Valid & $\begin{array}{l}\text { No. Butir } \\
\text { Valid }\end{array}$ & $\begin{array}{c}\text { Loading } \\
\text { Factor }\end{array}$ & Alpha Cronbach \\
\hline \multirow{20}{*}{$\begin{array}{l}\text { Pemalapetakaan } \\
\text { (catastrophizing) } \\
\text { dalam penyusunan } \\
\text { skripsi }\end{array}$} & \multirow{8}{*}{$\begin{array}{l}\text { Pemalapetakaan dalam penulisan } \\
\text { bagian-bagian skripsi } \\
\text { (loading factor: } 0,860 \text { ) }\end{array}$} & 8 & 0,869 & \multirow{20}{*}{0,955} \\
\hline & & 10 & 0,877 & \\
\hline & & 11 & 0,727 & \\
\hline & & 13 & 0,593 & \\
\hline & & 14 & 0,675 & \\
\hline & & 15 & 0,834 & \\
\hline & & 16 & 0,827 & \\
\hline & & 18 & 0,705 & \\
\hline & \multirow{5}{*}{$\begin{array}{l}\text { Pemalapetakaan dalam kegiatan } \\
\text { merevisi tulisan sebelumnya } \\
\text { (loading factor: } 0,736 \text { ) }\end{array}$} & 41 & 0,898 & \\
\hline & & 42 & 0,856 & \\
\hline & & 43 & 0,846 & \\
\hline & & 44 & 0,901 & \\
\hline & & 45 & 0,864 & \\
\hline & \multirow{4}{*}{$\begin{array}{l}\text { Pemalapetakaan dalam } \\
\text { kegiatan konsultasi pada dosen } \\
\text { pembimbing } \\
\text { (loading factor: } 0,877 \text { ) }\end{array}$} & 30 & 0,802 & \\
\hline & & 31 & 0,848 & \\
\hline & & 35 & 0,587 & \\
\hline & & 36 & 0,733 & \\
\hline & \multirow{3}{*}{$\begin{array}{l}\text { Pemalapetakaan dalam } \\
\text { penggunaan bahan pustaka } \\
\text { (loading factor: } 0,753 \text { ) }\end{array}$} & 1 & 0,844 & \\
\hline & & 3 & 0,893 & \\
\hline & & 6 & 0,810 & \\
\hline
\end{tabular}

tiga indikator. Butir 1;2; 5 dan 6 mengelompok dalam indikator perendahan diri dalam penggunaan bahan pustaka, butir $7 ; 8 ; 9 ; 10 ; 12 ; 14 ; 15$ dan 16 mengelompok dalam indikator perendahan diri dalam penulisan bagian-bagian skripsi, sedangkan butir 30; 32; 33; 34 dan 36 mengelompok dalam indikator perendahan diri terkait kegiatan konsultasi pada dosen pembimbing. Tujuh belas butir tersebut kemudian diuji reliabilitasnya dengan Alpha Chronbach. Hasil pengujian menunjukkan bahwa 17 butir tersebut reliabel karena memiliki koefisien Alpha Cronbach > 0,7. Hasil-hasil pengujian tersebut dirangkum dalam tabel 7.

Tujuh belas butir tersebut kemudian diuji kembali dengan analisis faktor konfirmatori untuk mengetahui unidimensionalitas model pengukuran dan validitas setiap butir. Berdasarkan hasil pengujian ini, diketahui bahwa $R M S E A=0,068$ yang berarti baik, serta nilai Chi-Square $=198,50$ dengan probabilitas sebesar 0,5971 yang berarti bahwa model pengukuran yang dikembangkan telah memperoleh dukungan empiris yang memadai. Demikian pula, lambda seluruh butir ke indikator dan indikator ke konstruk self-depreciation $>0,4$ yang berarti bahwa butir-butir dan indikator-indikator tersebut valid.

\section{Subskala Low Frustration Tolerance}

Pasca uji coba ahli, 45 butir subvariabel low frustration tolerance diuji secara statistik dengan menggunakan analisis faktor eksploratori; Alpha Chronbach; dan analisis faktor konfirmatori. Berdasarkan hasil pengujian dengan analisis faktor eksploratori, diperoleh dua puluh butir yang memiliki loading factor $\geq 0,5$ dan 25 butir yang memiliki loading factor $<0,5$. Dengan demikian, hanya tersisa dua puluh butir subvariabel low frustration tolerance yang valid. Dua puluh butir tersebut juga mengelompok dalam empat indikator. Butir 1; 2; 3; 5 dan 6 mengelompok dalam indikator toleransi rendah terhadap frustrasi terkait penggunaan bahan pustaka, butir $8 ; 10 ; 11 ; 12 ; 14$ dan 18 mengelompok dalam indikator toleransi rendah terhadap frustrasi dalam penulisan bagian-bagian skripsi, butir 28; 29;30; 31 dan 33 mengelompok dalam indikator toleransi rendah terhadap frustrasi dalam kegiatan konsultasi pada dosen pembimbing, sedangkan butir 37; 38; 39 dan 41 mengelompok dalam indikator toleransi rendah terhadap frustrasi dalam merevisi tulisan sebelumnya. Dua puluh butir tersebut kemudian diuji reliabilitasnya 
Tabel 7. Kisi-kisi Subskala Self-Depreciation Pasca Analisis Faktor Eksploratori dan Alpha Cronbach

\begin{tabular}{|c|c|c|c|c|}
\hline Subvariabel & Indikator Valid & $\begin{array}{c}\text { No. Butir } \\
\text { Valid }\end{array}$ & $\begin{array}{c}\text { Loading } \\
\text { Factor }\end{array}$ & Alpha Cronbach \\
\hline \multirow{17}{*}{$\begin{array}{l}\text { Tuntutan absolut } \\
\text { dalam kegiatan } \\
\text { konsultasi pada } \\
\text { dosen pembimbing } \\
\text { (loading factor: } \\
0,867 \text { ) }\end{array}$} & \multirow{8}{*}{$\begin{array}{l}\text { Perendahan diri dalam penulisan } \\
\text { bagian-bagian skripsi } \\
\text { (loading factor: } 0,908 \text { ) }\end{array}$} & 7 & 0,794 & \multirow{17}{*}{0,946} \\
\hline & & 8 & 0,881 & \\
\hline & & 9 & 0,585 & \\
\hline & & 10 & 0,849 & \\
\hline & & 12 & 0,926 & \\
\hline & & 14 & 0,811 & \\
\hline & & 15 & 0,721 & \\
\hline & & 16 & 0,574 & \\
\hline & \multirow{5}{*}{$\begin{array}{l}\text { Perendahan diri dalam } \\
\text { kegiatan konsultasi pada dosen } \\
\text { pembimbing } \\
\text { (loading factor: } 0,807 \text { ) }\end{array}$} & 30 & 0,733 & \\
\hline & & 32 & 0,772 & \\
\hline & & 33 & 0,830 & \\
\hline & & 34 & 0,847 & \\
\hline & & 36 & 0,876 & \\
\hline & \multirow{4}{*}{$\begin{array}{l}\text { Perendahan diri terkait } \\
\text { penggunaan bahan pustaka } \\
\text { (loading factor: } 0,771 \text { ) }\end{array}$} & 1 & 0,759 & \\
\hline & & 2 & 0,770 & \\
\hline & & 5 & 0,757 & \\
\hline & & 6 & 0,866 & \\
\hline
\end{tabular}

Tabel 8. Kisi-kisi Subskala Low Frustration Tolerance Pasca Analisis Faktor Eksploratori dan Alpha Cronbach

\begin{tabular}{llccc}
\hline \multicolumn{1}{c}{ Subvariabel } & \multicolumn{1}{c}{ Indikator Valid } & $\begin{array}{c}\text { No. Butir } \\
\text { Valid }\end{array}$ & $\begin{array}{c}\text { Loading } \\
\text { Factor }\end{array}$ & Alpha Cronbach \\
\hline Toleransi rendah & Toleransi rendah terhadap & 28 & 0,805 \\
pada frustrasi & frustrasi dalam kegiatan & 29 & 0,856 \\
(low frustration & konsultasi pada dosen & 30 & 0,821 \\
tolerance) dalam & pembimbing & 31 & 0,866 \\
penyusunan skripsi & (loading factor: 0,859) & 33 & 0,672 \\
& & 8 & 0,695 \\
& Toleransi rendah terhadap & 10 & 0,751 \\
& frustrasi dalam penulisan bagian- & 11 & 0,715 \\
& bagian skripsi & 12 & 0,705 \\
& (loading factor: 0,880) & 14 & 0,725 \\
& & 18 & 0,836 \\
& & 37 & 0,802 \\
& & 38 & 0,805 \\
& Toleransi rendah terhadap & 39 & 0,776 \\
& frustrasi dalam merevisi tulisan & 41 & 0,741 \\
& sebelumnya & 1 & 0,576 \\
& (loading factor: 0,794) & 2 & 0,630 \\
& & 3 & 0,795 \\
& Toleransi rendah terhadap & 5 & 0,717 \\
& frustrasi terkait penggunan & 6 & 0,736 \\
\hline bahan pustaka (loading factor: & 0,797) & &
\end{tabular}


dengan Alpha Chronbach. Hasil pengujian menunjukkan bahwa dua puluh butir tersebut reliabel karena memiliki koefisien Alpha Cronbach >0,7. Hasil-hasil pengujian tersebut dirangkum dalam tabel 8 .

Dua puluh butir tersebut kemudian diuji kembali dengan analisis faktor konfirmatori untuk mengetahui unidimensionalitas model pengukuran dan validitas setiap butir. Berdasarkan hasil pengujian analisis faktor konfirmatori, diketahui bahwa $R M S E A=0,045$ yang berarti baik, serta Chi-Square $=$ 169,05 dengan probabilitas sebesar 0,07903 yang berarti bahwa model pengukuran yang dikembangkan telah memperoleh dukungan empiris yang memadai. Demikian pula, lambda seluruh butir ke indikator dan indikator ke konstruk low frustration tolerance $>0,4$ yang berarti bahwa butir-butir dan indikatorindikator tersebut valid.

\section{PEMBAHASAN}

Setelah melalui proses uji coba yang ketat, penelitian ini menghasilkan 86 butir yang valid dan reliabel untuk mengukur keyakinan irasional dalam konteks penulisan skripsi. Butir-butir dimaksud juga telah memenuhi rekomendasi Terjesen dkk., (2009) yang menyebutkan bahwa pengembangan alat ukur keyakinan irasional sebaiknya memenuhi lima kriteria, yaitu: (1) instrumen hendaknya hanya mengukur aspek kognitif semata, tanpa bercampur dengan konsekuensi emotif atau behavioral; (2) instrumen hendaknya mengukur keyakinan rasional dan irasional secara terpisah karena keduanya bukan konstruk yang bipolar; (3) instrumen hendaknya mengukur dimensi dan konteks keyakinan irasional; dan (4) dalam proses pengembangannya, instrumen hendaknya menggunakan sampel yang bermacam-macam.

Butir-butir SKI-S satu persatu telah diseleksi dengan sedemikian rupa melalui uji ahli dan uji statistik agar hanya mengukur aspek kognitif keyakinan irasional saja. Upaya ini juga dilakukan agar instrumen tidak menyalahi konstruk keyakinan irasional yang telah dibangun oleh Ellis dkk., (2010). Misalnya butir "Jika kalimat-kalimat dalam skripsi saya berantakan, itu karena kemampuan saya memang di bawah rata-rata" dalam subskala self-depreciation, hanya mengukur aspek kognitif dari self-depreciation. Hal ini berbeda dengan butir "I often get excited or upset when things go wrong" dalam The Rational Behavior Inventory (RBI) (Shorkey \& Whiteman, 1977) yang mengukur aspek afektif atau butir "I avoid facing my problems" dalam The Irrational Beliefs Test (IBT) (Jones, 1968) yang mengukur aspek behavioral. Berdasarkan seleksi ketat tersebut, SKI-S ini dapat dikatakan telah memenuhi rekomendasi pertama yang disarankan oleh Terjesen dkk., (2009).

SKI-S terdiri dari beberapa subskala berdasarkan klasifikasi keyakinan irasional terbaru yang diajukan oleh Ellis dkk., (2010). Subskala-subskala tersebut adalah: subskala demandingness; subskala catastrophizing; subskala self-depreciation; dan subskala low frustration tolerance. Dengan pembagian demikian, SKI-S dapat menghasilkan skor total dan skor subskala. Dalam konteks layanan konseling dan penyelesaian masalah, skor subskala dapat dimanfaatkan untuk mengidentifikasi keyakinan irasional tertentu yang akan menjadi fokus intervensi. Beberapa instrumen terdahulu belum mengakomodasi klasifikasi keyakinan irasional terbaru ini. $B S$ misalnya, merupakan salah satu instrumen yang mengekstraksi butir-butirnya dari sepuluh jenis keyakinan irasional yang dikemukakan oleh Ellis \& Harper, (1961) pada periode awal pengembangan rational emotive behavioral therapy (REBT) (Malouff \& Schutte, 1986). Meskipun hal ini tidak menyalahi konstruk keyakinan irasional, namun instrumen tersebut lemah dari sisi efisiensi.

Untuk menjadi alat ukur yang baik, SKI-S menspesifikasikan diri sebagai alat ukur keyakinan irasional dan bukan keyakinan rasional. Karenanya, seluruh butir dalam SKI-S dikonstruksi dengan mengacu pada konsep irasionalitas saja. Skor total yang dihasilkan oleh SKI-S juga merupakan skor keyakinan irasional saja. Dengan kata lain, jika seseorang memperoleh skor yang tinggi setelah mengisi SKI-S, hal ini berarti ia memiliki keyakinan irasional yang kuat. Sebaliknya, jika ia memperoleh skor yang rendah, itu berarti bahwa keyakinan irasionalnya rendah, namun tidak berarti bahwa ia adalah individu yang rasional. Hasil-hasil penelitian telah menunjukkan bahwa rasionalitas dan irasionalitas merupakan konstruk yang berbeda sehingga harus diukur secara berbeda pula (Terjesen dkk., 2009). Salah satu instrumen populer yang telah merealisasikan pembedaan rasionalitas dan irasionalitas adalah $A B S$-II. $A B S$-II memiliki butir-butir yang secara khusus mengukur rasionalitas dan irasionalitas. Karena itu, salah satu keunggulan $A B S$-II adalah dapat menghasilkan skor rasionalitas dan irasionalitas secara berbeda. Sayangnya $A B S$-II juga dapat menghasilkan skor total, sehingga hal ini tidak sejalan dengan konsep perbedaan konstruk rasionalitas dan irasionalitas dimaksud. 
Salah satu keunggulan SKI-S dibandingkan dengan instrumen-instrumen lainnya adalah SKI-S mengukur keyakinan irasional dalam konteks yang spesifik, yaitu dalam penulisan skripsi. Beberapa instrumen lainnya menggunakan konteks umum sebagai tema instrumen. RAIBS, misalnya, menggunakan achievement; approval; comfort; justice; dan control sebagai tema dalam menyusun butirbutir (Mogoase dkk., 2013). Hal ini dilakukan dengan harapan agar RAIBS dapat digunakan dalam konteks yang luas. Dibalik keluasannya, RAIBS diduga kurang dapat mengukur konteks yang lebih spesifik. Dengan alasan inilah, SKI-S dikonstruksi dengan konteks yang sangat spesifik. Hal ini tentu saja dapat menjadi kelebihan sekaligus kekurangan SKI-S. Sebagai kelebihan, SKI-S dapat mengukur irasionalitas dengan tepat dalam konteks penulisan skripsi. Sebaliknya, kekurangan SKI-S adalah tidak dapat digunakan untuk mengukur konteks-konteks lainnya.

Kekurangan lain SKI-S adalah jumlah dan homogenitas sampel yang digunakan. Jumlah sampel 200 mahasiswa yang berasal dari satu universitas merupakan kelemahan yang perlu diperbaiki dalam penelitian-penelitian selanjutnya. Instrumen yang baik seharusnya menggunakan sampel yang besar dan beragam, sehingga hasilnya dapat dimanfaatkan oleh pengguna yang relatif luas. $A B S$ merupakan salah satu contoh alat ukur keyakinan irasional yang telah divalidasi berkali-kali dengan sampel yang besar dan beragam. Karenanya, instrumen ini sangat populer dan memiliki berbagai versi mulai dari $A B S$-I, $A B S$-II, dan $A V-A B S$ ( $A B S$ versi ringkas) (Hyland, dkk., 2014).

\section{SIMPULAN}

Proses konstruksi dan validasi SKI-S menghasilkan 86 butir valid dan reliabel yang terbagi menjadi: 16 butir subskala demandingness; 20 butir subskala catastrophizing; 17 butir subskala selfdepreciation; dan 20 butir subskala low frustration tolerance. Butir-butir tersebut mengukur keyakinan irasional sesuai dengan konstruk yang dikemukakan oleh Albert Ellis, founder REBT. Pembagian subskala-subskala SKI-S menjadi empat bagian mengacu pada klasifikasi keyakinan irasional terbaru yang dikemukan oleh Albert Ellis berdasarkan abstraksi dari sejumlah penelitian. Dengan demikian, SKI-S dapat menghasilkan skor total keyakinan irasional dan skor subskala.

\section{DAFTAR RUJUKAN}

Balkis, M., Duru, E., \& Bulus, M. (2013). Analysis of The Relation Between Academic Procrastination, Academic Rational/Irrational Beliefs, Time Preferences to Study for Exams, and Academic Achievement: A Structural Model. European Journal of Psychology of Education, 28(3), 825-839. https://doi.org/10.1007/s10212-0120142-5

Burgess, P. M. (1986). Belief Systems and Emotional Disturbance: An Evaluation of The Rational-Emotive Model. University of Melbourne.

DiGiuseppe, R., Leaf, R., Gorman, B., \& Robin, M. W. (2018). The Development of A Measure of Irrational/ Rational Beliefs. Journal of Rational-Emotive \& Cognitive-Behavior Therapy, 36(1), 47-79.

Dryden, W. (2012). Dealing with Procrastination: The REBT Approach and A Demonstration Session. Journal of Rational-Emotive \& Cognitive-Behavior Therapy, 30(4), 264-281.

Dryden, W., \& Neenan, M. (2004). Rational Emotive Behavioural Counselling in Action. Sage.

Ellis, A., David, D., \& Lynn, S. J. (2010). Rational and Irrational Beliefs: A Historical and Conceptual Perspective. Rational and Irrational Beliefs: Research, Theory, and Clinical Practice, 3-22.

Ellis, A., \& Harper, R. A. (1961). A Guide to Rational Living.

Ferdinand, A. (2002). Structural Equation Modeling dalam Penelitian Manajemen. Semarang: Badan Penerbit Universitas Diponegoro.

Hair, J. F., Black, W. C., Babin, B. J., Anderson, R. E., \& Tatham, R. L. (2006). Multivariate Data Analysis (6th Edition. New Jersey: Prentice Hall.

Harrington, N. (2005). It's Too Difficult! Frustration Intolerance Beliefs and Procrastination. Personality and Individual Differences, 39(5), 873-883.

Hyland, P., Shevlin, M., Adamson, G., \& Boduszek, D. (2014). Modeling The Structure of The Attitudes and Belief Scale 2 using CFA and Bifactor Approaches: Toward The Development of An Abbreviated Version. Cognitive Behaviour Therapy, 43(1), 60-71.

Jones, R. G. (1968). A Factored Measure of Ellis' Irrational Belief System with Personality and Maladjustment Correlates. Texas Tech University. 
Malouff, J. M., \& Schutte, N. S. (1986). Development and Validation of A Measure of Irrational Belief. Journal of Consulting and Clinical Psychology, 54(6), 860.

Mogoase, C., Stefan, S., \& David, D. (2013). How Do We Measure Rational and Irrational Beliefs? The Development of Rational and Irrational Beliefs Scale (RAIBS)-A New Theory-Driven Measure. Journal of Evidence-Based Psychotherapies, 13(2A), 529.

Ozer, B. U., Demir, A., \& Ferrari, J. R. (2013). Reducing Academic Procrastination Through A Group Treatment Program: A Pilot Study. Journal of Rational-Emotive \& Cognitive-Behavior Therapy, 31(3), 127-135.

Rahman, D. H. (2016). Integrating Al-Qur'an with Rational Emotive Behavior Therapy in Counseling Muslim Students. Dalam 2nd ICET Theme: "Improving The Quality of Education and Training Through Strengthening Networking” (hal. 211-216). Malang.

Shorkey, C. T., \& Whiteman, V. L. (1977). Development of The Rational Behavior Inventory: Initial Validity and Reliability. Educational and Psychological Measurement, 37(2), 527-534.

Szentagotai, A., \& Jones, J. (2010). The Behavioral Consequences of Irrational Beliefs. Dalam D. David, S. J. Lynn, \& A. Ellis (Ed.), Rational and Irrational Beliefs: Research, Theory, and Clinical Practice (hal. 75-97). New York, NY, US: Oxford University Press.

Terjesen, M. D., Salhany, J., \& Sciutto, M. J. (2009). A Psychometric Review of Measures of Irrational Beliefs: Implications for Psychotherapy. Journal of Rational-Emotive \& Cognitive-Behavior Therapy, 27(2), 83-96. 